\title{
Dental Students' Perceptions of and Experiences with Prosthodontics: Ten Graduating Classes at One Institution
}

\author{
Jane H. Shin, DMD; Taru H. Kinnunen, PhD; Marisa Zarchy, DMD; John D. Da Silva, \\ DMD, MPH, ScM; Brian Myung W. Chang, DDS; Robert F. Wright, DDS
}

Abstract: It is important for members of the dental specialties to understand what motivates students to enter the specialty in order to ensure its continuing development and ability to meet patient needs. The aim of this study was to compare ten graduating classes at Harvard School of Dental Medicine (HSDM) regarding students' experiences with and perceptions of prosthodontics and factors influencing those interested in pursuing prosthodontics as a specialty. In 2013, HSDM students in the classes of 201216 were surveyed, achieving a response rate of $81 \%$. Survey questions sought information regarding specialty choice, factors influencing the choice, student experiences with prosthodontics, and student perceptions of the dental disciplines. Responses were compared to those from a prior study of the HSDM classes of 2007-11. The responses showed a decrease in negative student experiences with prosthodontics. The students regarded prosthodontics highly for its impact on patient quality of life; however, students interested in pursuing prosthodontics as a specialty decreased. All students said provider enjoyment was most important in choice of specialty. Cost of program, patient type, and program location were factors that especially influenced students interested in prosthodontics. The improved student experiences with and perspectives on prosthodontics may be a result of a curriculum change that led to more prosthodontics procedures and case completions by students. The fall in students interested in prosthodontics may have resulted from prosthodontic faculty transitions that occurred when the survey was conducted, as well as large debt burdens in spite of the fact that prosthodontists' earnings are among the highest in dentistry. Faculty must educate and mentor students about the realities of the profession, provide positive learning experiences in the field, and encourage students who enjoy prosthodontics to pursue specialty training.

Dr. Shin is a postdoctoral periodontics resident at Columbia University College of Dental Medicine; Dr. Kinnunen is Assistant Professor, Department of Oral Health Policy and Epidemiology, Harvard School of Dental Medicine; Dr. Zarchy is a practicing endodontist in Lansdale, Pennsylvania; Dr. Da Silva is Vice Dean and Assistant Professor, Department of Restorative Dentistry and Biomaterials Sciences, Harvard School of Dental Medicine; Dr. Chang is Section Head, Maxillofacial Prosthodontics, Cleveland Clinic Head and Neck Institute; and Dr. Wright is Professor and Chair, Department of Prosthodontics, University of North Carolina at Chapel Hill School of Dentistry. Direct correspondence to Dr. Robert F. Wright, Department of Prosthodontics, University of North Carolina at Chapel Hill, School of Dentistry, 335 Brauer Hall, Campus Box 7450, Chapel Hill, NC 275997450; 919-537-3435; robert_wright@unc.edu.

Keywords: dental students, prosthodontics, dental education, postgraduate dental education, dental specialties, mentors

Submitted for publication 4/14/14; accepted 6/25/14

$\mathrm{F}$ rom 2002 to 2013, although the number of U.S. specialty programs in prosthodontics remained the same, the first-year enrollment in those programs increased $7 \%$, and the number of applicants to them more than doubled. ${ }^{1}$ The increases are partly due to the increase in U.S.-trained applicants to prosthodontics programs during this time. ${ }^{2}$ An example of this trend was evident in the dramatic increase in Harvard School of Dental Medicine (HSDM) graduates entering prosthodontics programs: while only six HSDM graduates pursued prosthodontics specialty training from the classes of 1994 to 2004, 19 HSDM graduates chose to specialize in prosthodontics from the classes of 2005 to 2011.

Zarchy et al. reported that $5.4 \%$ of respondents (nine out of 167 students) in the HSDM classes of 2007-11 planned to pursue specialty training in prosthodontics. ${ }^{3}$ In contrast, a concurrent study at the University of Pennsylvania School of Dental Medicine (UPennSDM) showed that $51 \%$ of their 410 respondents did not plan to specialize and only $1.7 \%$ planned to specialize in prosthodontics. ${ }^{4}$ HSDM prosthodontics interest was about three times that of UPennSDM. Therefore, it is noteworthy to examine the differences in student perspectives on prosthodontics at these two dental schools. At UPennSDM, although a preclinical course directed by an educationally qualified prosthodontic faculty member was the single most favorable introductory experience to prosthodontics, very few of the other faculty members at UPennSDM received training at Commission on Dental Accreditation (CODA)accredited prosthodontic graduate programs. ${ }^{5}$ Moreover, UPennSDM does not have a prosthodontics 
graduate training program, limiting students' full exposure to the specialty. Finally, at the time of this study, UPennSDM did not have an established prosthodontic mentorship program.

Studies have shown that mentoring by prosthodontics faculty at the predoctoral level has contributed to the increased number of applicants to postdoctoral prosthodontics programs. ${ }^{6,7}$ Unlike UPennSDM, HSDM has a postgraduate program in prosthodontics, and changes were implemented to promote greater prosthodontics graduate student and faculty involvement in predoctoral dental education. Teaching and mentoring in the postgraduate prosthodontics program was added as a formal program, and the written portion of the American Board of Prosthodontics (ABP) examination and a clinical presentation for a mock board were added requirements for graduation. Moreover, the postgraduate program at HSDM increased efforts to recruit top U.S. and internationally trained students. ${ }^{3}$

At the predoctoral level, the Harvard Prosthodontics Study Club was founded in 2004 to increase dental student exposure to topics in prosthodontics through lectures given by postgraduate prosthodontics students and prominent guests in the field. The prosthodontics program director was also appointed course director for oral physiology taught in the first year, a time in the curriculum when most other courses are taught at Harvard Medical School. The predoctoral director of prosthodontics, an ABPcertified prosthodontist who has won numerous faculty awards for teaching, led the changes in the predoctoral curriculum. ${ }^{3}$

Studies have shown a positive statistically significant correlation between an increase in the number of applicants to prosthodontics programs and mentoring by prosthodontists at the predoctoral level. ${ }^{2,6-8}$ The changes made at HSDM allowed for greater mentoring potential by the prosthodontics faculty. Additionally, the prosthodontics faculty members provided opportunities for predoctoral students to participate in educational and materials science research, leading to predoctoral student presentations at national and international prosthodontics meetings. Ultimately, these changes were thought to have contributed greatly to the increased HSDM student interest in prosthodontics. ${ }^{3}$

At both HSDM and UPennSDM, however, students did not rank prosthodontics very highly in terms of personal quality of life and salary. This was surprising given that the annual mean wage for prosthodontists is highest after those of oral and max- illofacial surgeons and orthodontists. ${ }^{9}$ And although prosthodontics can be a challenging specialty, the impact of prosthodontic treatment on patients can be extremely rewarding. Examining UPennSDM and HSDM dental student perspectives on specialties has given us insight into current shortcomings in prosthodontics mentoring at dental schools and the effectiveness of programs already in place. By understanding and addressing these issues, we can help prevent a future shortage of prosthodontic services.

The aims of this study were, first, to survey HSDM classes of 2012-16 to assess the students' experiences with prosthodontics, perceptions of prosthodontics, and factors influencing students who decided to pursue specialty training in prosthodontics and, second, to compare the findings with those from our prior study of the classes of 2007-11, ${ }^{3}$ for a total of ten graduating classes of HSDM students. During the time this survey was conducted, improvements made to the postgraduate and predoctoral prosthodontics curricula were maintained. At the same time, however, the postgraduate prosthodontics program director and predoctoral prosthodontics director who led these changes were preparing to leave HSDM for positions at different institutions, and interim directors filled those leadership positions. New, highly talented clinical faculty members, who graduated from either the HSDM predoctoral program or HSDM postgraduate prosthodontics program, were also introduced to the predoctoral prosthodontic curriculum. HSDM has, in recent years, made a concerted effort to have talented, educationally qualified prosthodontists assigned to predoctoral teaching. Moreover, a case completion curriculum replaced the discipline-based numeric threshold system at HSDM in 2009. We analyzed our survey data as to how these changes may have affected responses from the classes of 2012-16 when compared to those from the classes of 2007-11.

\section{Materials and Methods}

The research protocol for this study was reviewed and approved by the Harvard Medical School Committee on Human Studies as exempted research (IRB13-0408). In 2013, we distributed the same survey developed for our prior study conducted in $2008^{3}$ to 176 currently enrolled students (classes of 2013 to 2016) and recent graduates (class of 2012) of HSDM. Similarly, our 2008 study $^{3}$ was conducted with 176 currently enrolled students (classes of 2008-11) and recent graduates (class of 2007) of HSDM at the time. 
An Internet-based survey program (KeySurvey, Inc., Braintree, MA) was utilized to distribute and process completed surveys, validate and submit follow-up emails to nonrespondents, and store the resulting data in an electronic Microsoft Excel format. The survey was configured to allow only one response per respondent email address. Each potential survey respondent was given a unique link to the survey software to monitor progress and completion of the survey. Respondents were allowed to skip answers as they wished. The respondents completed the survey anonymously and voluntarily. Included in the email containing the survey link were a cover letter explaining the purpose of the survey, a statement of confidentiality, and notice of approval from and a contact at the Office for Research Subject Protection at Harvard Medical School. Respondent information collected included class year and amount of debt expected to be accrued by the end of dental school. Survey questions were designed to generate information regarding students' specialty choice, factors that influenced their choice, experiences with prosthodontics in dental school, and perception of prosthodontics and other dental disciplines.

Statistical analysis was carried out in STATISTICA v.10 (StatSoft Inc., Tulsa, OK). Raw data were directly extracted from the KeySurvey database. Descriptive statistics are reported as proportions for categorical variables, with chi-square tests performed when contingency tables had any cell size $\mathrm{n}>10$ and Fisher exact test when $\mathrm{n}<10$. Additional descriptive statistics are reported as rank orders and frequency distributions for which no statistical tests were performed.

\section{Results}

Of 176 HSDM students from the classes of 2012-16, 143 responded to the survey, for a response rate of $81 \%$. In the study conducted in $2008,{ }^{3} 167$ out of 176 HSDM students from the classes of 2007-11 responded to the survey, for a response rate of $95 \%$. Although students were given the option to skip questions, there was at least a $90 \%$ response rate for each question answered by the 143 students who participated in the survey. The same was the case for our prior study conducted in 2008.

\section{Students' Experience with Prosthodontics}

A majority (70\%) of students in the classes of 2012-16 reported positive experiences with prosthodontics (Figure 1). Only $7 \%$ of students in those years reported negative experiences with prosthodontics. This is lower than the $13 \%$ of students reporting negative experiences with the specialty in the classes of 2007-11. The majority of the respondents' first introduction to prosthodontics was through the faculty

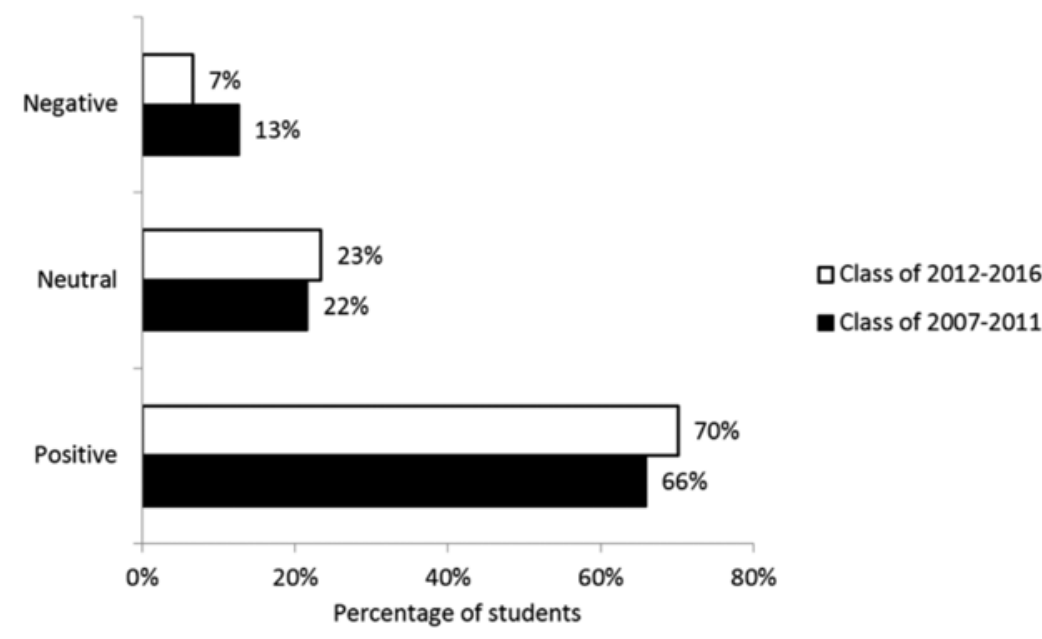

Figure 1. HSDM students' perceptions of their introductory experience with prosthodontics, by percentage of total respondents in each survey group 
member teaching lecture ( $52 \%$ of classes of $2007-11$, $50 \%$ of classes of 2012-16) (data not shown).

Of the introductory experiences to prosthodontics having the biggest impact, experiences in the category of faculty/mentoring were selected by the greatest percentage of students $(44 \%)$; this is an increase from $37 \%$ in the 2008 study (Table 1). Those who reported that didactics experiences had the biggest influence fell from $28 \%$ to $20 \%$. When students were asked about their clinical experiences related to prosthodontics at HSDM, we saw notable decreases in the percentage of negative responses, as well as slight increases in the percentage of positive responses (Table 2). However, students' awareness of the future need for prosthodontists decreased from $85 \%$ among students in the classes of 2007-11 to $78 \%$ among students in the classes of 2012-16 (data not shown). This goes along with the decrease in the percentage of students in the classes of 2012-16 who responded that the future need for prosthodontics has been stressed at school (Table 2).

\section{Perceptions and Choice of Prosthodontics}

Respondents were asked to choose one of the nine American Dental Association (ADA)- recognized specialties or general dentistry regarding four different measures. Prosthodontics received the second greatest percentage of votes by the classes of 2012-16 for impact on patient's quality of life, compared to the fifth greatest percentage of votes by the classes of 2007-11 (Table 3). For all other measures, prosthodontics received the fifth greatest number of votes, which was similar to the way the classes of 2007-11 voted, with a slight decrease in rank for the perception of prosthodontics salary.

Regarding the pursuit of specialty education, $85 \%$ of the classes of $2012-16$ and $87 \%$ of the classes of 2007-11 planned to specialize. Only $4 \%$ of students in the classes of 2012-16 planned to pursue prosthodontics, compared to $7 \%$ of students in the classes of 2007-11 (data not shown). The largest percentage of students chose enjoyment of providing that type of specialty service as the factor that impacted their dental career choice. This was also the factor that impacted the greatest percentage of students interested in prosthodontics (Figure 2). In fact, of all dental disciplines, prosthodontics had the greatest percentage of students (93\%) indicating that this factor impacted their specialty choice (data not shown). That factor was followed by future salary and faculty influence for all students as well as those interested in prosthodontics. Cost of program,

Table 1. Introductory experiences to prosthodontics that had the biggest impact on HSDM students, by number and percentage of total respondents in each survey group

Classes of 2007-11

Classes of 2012-16

\begin{tabular}{|c|c|c|c|c|}
\hline Factor & Number & Percentage & Number & Percentage \\
\hline Faculty/mentoring: total & 62 & $37 \%$ & 58 & $44 \%$ \\
\hline Faculty member teaching lecture & 38 & $23 \%$ & 40 & $30 \%$ \\
\hline Faculty member outside of lecture & 9 & $5 \%$ & 4 & $3 \%$ \\
\hline Faculty member in clinic & 15 & $9 \%$ & 14 & $11 \%$ \\
\hline Didactics: total & 47 & $28 \%$ & 27 & $20 \%$ \\
\hline Preclinical course directed by prosthodontists & 38 & $23 \%$ & 25 & $19 \%$ \\
\hline Clinical course taught by prosthodontists & 9 & $5 \%$ & 2 & $2 \%$ \\
\hline Hands-on experience: total & 41 & $25 \%$ & 33 & $25 \%$ \\
\hline Working in the clinic & 35 & $21 \%$ & 20 & $15 \%$ \\
\hline Working in a commercial or school laboratory & 6 & $4 \%$ & 13 & $10 \%$ \\
\hline Other: total & 17 & $10 \%$ & 15 & $11 \%$ \\
\hline Textbook/dental journals/online dental website & 4 & $2 \%$ & 2 & $2 \%$ \\
\hline As a patient & 4 & $2 \%$ & 2 & $2 \%$ \\
\hline Other & 9 & $5 \%$ & 11 & $8 \%$ \\
\hline Total responses & 167 & $100 \%$ & 133 & $100 \%$ \\
\hline
\end{tabular}

Note: Experiences were collapsed into four categories: Faculty/mentoring, Didactics, Hands-on experience, and Other. In the Other category, students had the opportunity to write in other introductory experiences to prosthodontics. These included shadowing non-faculty dentists, working with residents, family in the field, and summer programs. 
Table 2. Summary of HSDM students' perceptions of their experiences with prosthodontics during dental school, by number and percentage of total respondents in each survey group for each question

\begin{tabular}{|c|c|c|c|c|c|}
\hline & & \multicolumn{2}{|c|}{ Classes of $2007-11$} & \multicolumn{2}{|c|}{ Classes of 2012-16 } \\
\hline & & Number & Percentage & Number & Percentage \\
\hline \multirow[t]{5}{*}{ a) } & Experience with prosthodontic/restorative faculty positive? & & & & \\
\hline & Yes & 123 & $74 \%$ & 99 & $76 \%$ \\
\hline & Indifferent & 30 & $18 \%$ & 27 & $21 \%$ \\
\hline & No & 14 & $8 \%$ & 5 & $4 \%$ \\
\hline & Total & 167 & $100 \%$ & 131 & $100 \%$ \\
\hline \multirow[t]{5}{*}{ b) } & Do you enjoy doing dental laboratory work? & & & & \\
\hline & Yes & 78 & $47 \%$ & 68 & $50 \%$ \\
\hline & Indifferent & 37 & $22 \%$ & 35 & $26 \%$ \\
\hline & No & 52 & $31 \%$ & 33 & $24 \%$ \\
\hline & Total & 167 & $100 \%$ & 136 & $100 \%$ \\
\hline \multirow[t]{5}{*}{ c) } & Do you enjoy complicated/challenging restorative dentistry? & & & & \\
\hline & Yes & 91 & $54 \%$ & 75 & $55 \%$ \\
\hline & Indifferent & 42 & $25 \%$ & 44 & $32 \%$ \\
\hline & No & 34 & $20 \%$ & 17 & $13 \%$ \\
\hline & Total & 167 & $100 \%$ & 136 & $100 \%$ \\
\hline \multirow[t]{5}{*}{ d) } & Has the future need for prosthodontics been stressed at your school? & & & & \\
\hline & Yes & 114 & $68 \%$ & 77 & $55 \%$ \\
\hline & Indifferent & 36 & $22 \%$ & 51 & $37 \%$ \\
\hline & No & 17 & $10 \%$ & 11 & $8 \%$ \\
\hline & Total & 167 & $100 \%$ & 139 & $100 \%$ \\
\hline
\end{tabular}

Table 3. HSDM students' highest ranking of the nine dental specialties on four measures, plus the ranking of prosthodontics for each

\begin{tabular}{|c|c|c|c|c|}
\hline \multirow[b]{2}{*}{ Measure } & \multirow[b]{2}{*}{ Classes of 2007-11 } & \multirow[b]{2}{*}{ Classes of 2012-16 } & $\begin{array}{l}\text { Classes of } \\
2007-11\end{array}$ & $\begin{array}{l}\text { Classes of } \\
\text { 2012-16 }\end{array}$ \\
\hline & & & \multicolumn{2}{|c|}{ Prosthodontics Rank } \\
\hline Salary & Oral and maxillofacial surgery & Oral and maxillofacial surgery & 4th & 5 th \\
\hline Dentist's quality of life & $\begin{array}{l}\text { Orthodontics and dentofacial } \\
\text { orthopedics }\end{array}$ & $\begin{array}{l}\text { Orthodontics and dentofacial } \\
\text { orthopedics }\end{array}$ & 5 th & 5 th \\
\hline Patient's quality of life & $\begin{array}{l}\text { Orthodontics and dentofacial } \\
\text { orthopedics }\end{array}$ & Oral and maxillofacial surgery & 5 th & 2nd \\
\hline $\begin{array}{l}\text { Impact on patient's } \\
\text { overall care }\end{array}$ & Oral and maxillofacial surgery & General dentistry & 5 th & 5 th \\
\hline
\end{tabular}

types of patients seen in the specialty of service, and location of advanced education program were factors that influenced students interested in prosthodontics statistically significantly more than students interested in other dental disciplines $(p=0.04, p=0.13$, $\mathrm{p}=0.10$, respectively).

We then looked at the amount of debt students expected to accrue by dental school graduation. The largest percentage of students expected to accrue $\$ 201,000-\$ 250,000$ in debt by the time they gradu- ate. This was also the case for students interested in prosthodontics. In fact, a larger percentage of students interested in prosthodontics expected to accrue this much in debt, compared to the percentage of all students (Figure 3). The next largest percentage of students interested in prosthodontics expected to accrue no debt by the time they graduate. The percentage of students interested in prosthodontics with no debt was higher than the percentage of all students with no debt. 


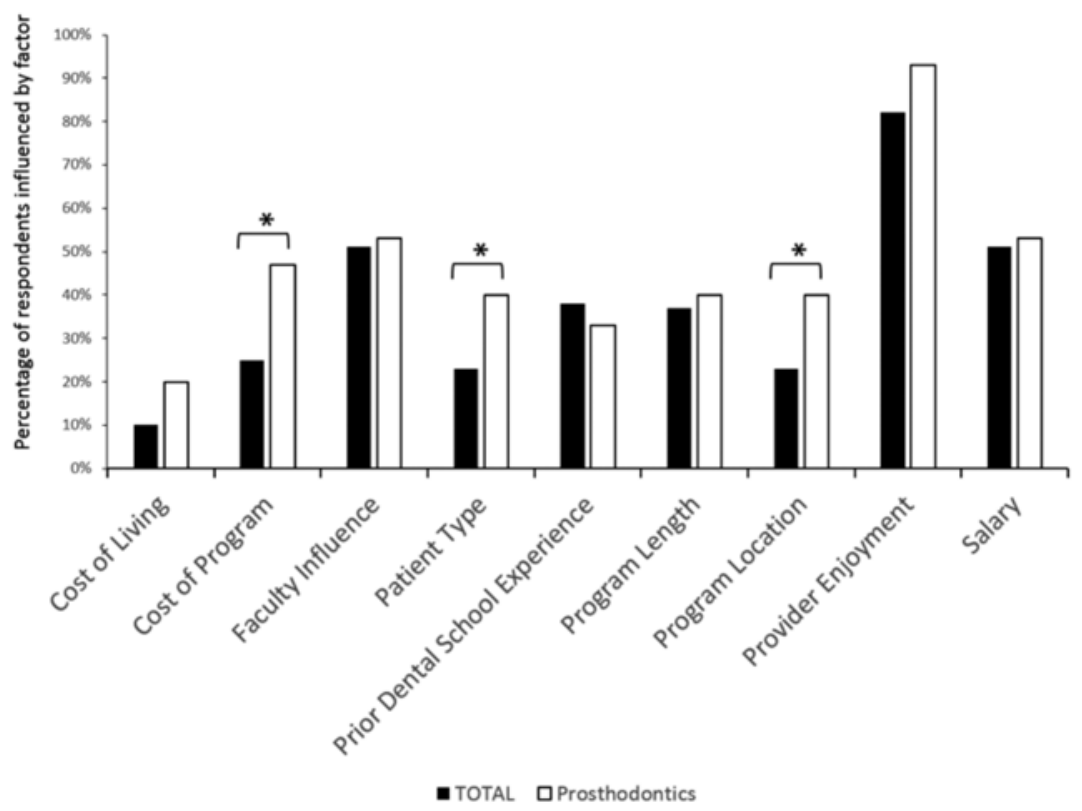

Figure 2. Factors that influenced student specialty choice, by percentage of total respondents and by percentage of those interested in pursuing prosthodontics (total of Classes of 2007-11 and 2012-16)

Note: Significance determined by chi-square test when contingency tables had any cell size $\mathrm{n}>10$ and Fisher exact test when $\mathrm{n}<10$. ${ }^{*} \mathrm{p}=0.04, \mathrm{p}=0.13$, and $\mathrm{p}=0.10$ for cost of program, patient type, and program location, respectively

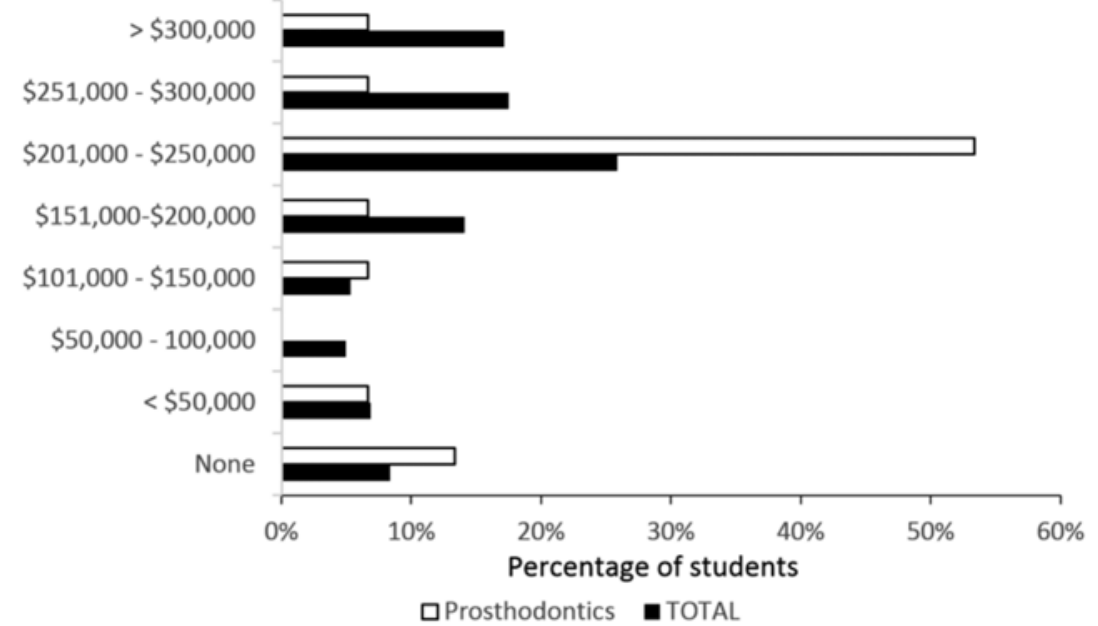

Figure 3. Debt expected to be accrued upon dental school graduation by HSDM students and by only those interested in pursuing prosthodontics (total of Classes of 2007-11 and 2012-16) 


\section{Discussion}

This study found decreases in negative student experiences and increases in positive student experiences with prosthodontics at HSDM (Figure 1, Table 2). Moreover, prosthodontics received the second highest number of votes in the classes of 2012-16 as the specialty having the greatest impact on patient quality of life (Table 3 ). A case completion curriculum replaced the discipline-based numeric threshold system at HSDM in 2009, resulting in students' completing a greater number of operative and removable prosthodontics procedures..$^{10}$ Moreover, the average number of cases completed per student increased from 12.8 to $22.8 .{ }^{11}$ With this curriculum change, students had greater exposure to the clinical work of prosthodontists and were able to more often experience the satisfaction patients and providers feel when seeing cases through from beginning to end. These factors could have contributed to the overall improvements in student experiences with and perspectives on prosthodontics.

However, there was a decrease in the number of students planning to pursue prosthodontics as a specialty, as well as a decrease in students who believed there was a future need for prosthodontists. The latest ADA research demonstrates otherwise: dental care utilization has steadily increased among the elderly since $2000 .^{12}$ Thirty million patients are predicted to be edentulous by the year $2020^{13}$ and will need prosthodontic treatment to restore a new dentition. In addition, a downward trend in edentulism ${ }^{13}$ suggests there will be a greater demand and need for dental care in the future, particularly for prosthodontic treatment to help maintain existing teeth. There was a slight fall in students' rank of prosthodontics salary (Table 3), indicating a possible lack of awareness that prosthodontists have one of the highest annual mean wages among dental specialists. ${ }^{9}$

Furthermore, the decrease in respondents indicating that the need for prosthodontists was stressed at HSDM (Table 2) and the decrease in the impact of didactics on students' introductory experience to prosthodontics (Table 1) may have been a result of the fact that the survey was conducted during a time of faculty transitions in the prosthodontics department. Faculty influence was chosen as an impacting factor by a high percentage of students interested in prosthodontics, as well as by a high percentage of all students (Figure 2), so it is important for faculty members to take advantage of this opportunity to educate students about the need for prosthodontists. Although HSDM was successful in hiring a well-qualified group of new faculty members, more needs to be done by dental schools nationally to ensure recruitment and retention of full-time dental educators, ${ }^{14}$ especially because faculty influence and mentoring can have a great influence on student career choice.

For these two periods, there was a drop from $7 \%$ to $4 \%$ in HSDM students interested in prosthodontics as a specialty. Future salary was an important factor influencing students interested in prosthodontics as well as for those interested in other dental disciplines (Figure 2). The economic downturn, ${ }^{15}$ rising dental school tuition, ${ }^{16}$ and greater educational debt burden that students face upon graduation ${ }^{17}$ may have discouraged students from pursuing a specialty such as prosthodontics, even though they reported positive experiences within the field during dental school, especially since many prosthodontics programs charge tuition or offer only a small stipend. ${ }^{1}$ Therefore, students interested in pursuing prosthodontics were especially influenced by the cost of program factor.

At the same time, however, most of the students interested in prosthodontics did so despite their high student debt (Figure 3). It is important to remember that enjoyment of providing that type of specialty service influenced the greatest percentage of students, and those students interested in prosthodontics had the greatest percentage indicating that this was an impacting factor (Figure 2). The hands-on nature of prosthodontic treatment makes this an understandably important influencing factor for prosthodontics students. Furthermore, prosthodontics requires a great deal of patient interaction and communication throughout long-term treatment plans, a reason why the patient type factor was especially important to students interested in prosthodontics. To go along with this, these students were also more impacted by location of the program, possibly because of factors such as patient demographic, culture, socioeconomic class, and saturation of dental providers within the community that can affect the range of prosthodontic treatments that can be delivered.

\section{Conclusion}

This study comparing ten graduating classes at HSDM demonstrated positive changes in predoctoral student experiences with and perceptions of prosthodontics. This occurred during important curriculum 
changes that led to greater student clinical experiences with providing restorative and prosthodontic treatments. Yet the daunting amount of debt that students face upon dental school graduation may be deterring them from taking on the immediate costs of prosthodontics training. However, average annual earnings for prosthodontists are among the highest in dentistry, and data indicate that prosthodontists are in high need. In addition, although there has been an increase in U.S.-trained applicants enrolled in prosthodontics programs, the percentage of U.S.trained dentists in prosthodontics programs is still much lower than that seen for other dental disciplines. Dental school faculty members are in a great position to educate and mentor students about the realities of the profession and provide positive learning experiences in restorative and prosthodontic treatment to encourage students who enjoy prosthodontics to pursue a career in this specialty.

\section{Acknowledgments}

The survey instrument was developed by Dr. Marisa Zarchy as part of her research mentorship during her time at Harvard School of Dental Medicine with her research mentor, Dr. Robert F. Wright, who was advanced graduate education prosthodontics program director at HSDM at the time. Funding was provided by the Harvard School of Dental Medicine Prosthodontics Research Fund, Division of Prosthodontics.

\section{REFERENCES}

1. American Dental Association, Health Policy Resources Center. Survey of advanced dental education. Chicago: American Dental Association, 2014.

2. Munoz DM, Kinnunen T, Chang BM, Wright RF. Tenyear survey of program directors: trends, challenges, and mentoring in prosthodontics, part 1. J Prosthodont 2011;20(7):587-92.

3. Zarchy M, Kinnunen T, Chang BM, Wright RF. Increasing predoctoral dental students' motivations to specialize in prosthodontics. J Dent Educ 2011;75(9):1236-43.
4. Dhima M, Petropoulos VC, Han RK, et al. Dental students' perceptions of dental specialties and factors influencing specialty and career choices. J Dent Educ 2012;76(5): 562-73.

5. Dhima M, Petropoulos VC, Salinas TJ, Wright RF. Predoctoral dental students' perceptions and experiences with prosthodontics. J Prosthodont 2013;22(2):148-56.

6. Wright RF, Dunlop RA, Kim FM, Douglass CW. A survey of program directors: trends, challenges, and mentoring in prosthodontics, part 1. J Prosthodont 2008;17(1):69-75.

7. Wright RF, Dunlop RA, Kim FM, et al. A survey of deans: trends, challenges, and mentoring in prosthodontics, part 2. J Prosthodont 2008;17(2):149-55.

8. Haden NK, Weaver RG, Valachovic RW. Meeting the demand for future dental school faculty: trends, challenges, and responses. J Dent Educ 2002;66(9):1102-13.

9. U.S. Department of Labor, Bureau of Labor Statistics. National occupational employment and wage estimates, May 2012. At: www.bls.gov/oes/current/oes_nat.htm\#000000. Accessed: 26 Mar. 2014.

10. Park SE, Susarla HK, Nalliah R, et al. Does a case completion curriculum influence dental students' clinical productivity? J Dent Educ 2012;76(5):602-8.

11. Park SE, Timothé P, Nalliah R, et al. A case completion curriculum for clinical dental education: replacing numerical requirements with patient-based comprehensive care. J Dent Educ 2011;75(11):1411-6.

12. Nasseh K, Vujicic M. Dental care utilization continues to decline among working-age adults, increases among the elderly, stable among children. Health Policy Resources Center research brief. Chicago: American Dental Association, 2013.

13. Douglass CW, Shih A, Ostry L. Will there be a need for complete dentures in the United States in 2020? J Prosthet Dent 2002;87(1):5-8.

14. Vanchit J, Papageorge M, Jahangiri L, et al. Recruitment, development, and retention of dental faculty in a changing environment. J Dent Educ 2011;75(1):82-9.

15. Vujicic M, Wall TP, Nasseh K, Munson B. Dentist income levels slow to recover. Health Policy Resources Center research brief. Chicago: American Dental Association, 2013.

16. American Dental Association. 2010-11 survey of dental education: tuition, admission, and attrition. Chicago: American Dental Association, 2012.

17. Stafford GL. Dental student indebtedness: where did it come from and where will it lead? J Am Coll Dent 2013;80(4):38-48. 